\title{
Simulasi Penjualan Arang Batok Kelapa dengan Menggunakan Metode Monte Carlo Pada CV. Banjar Berniaga
}

\author{
Musthafa Haris Munandar'), Masrizal ${ }^{2)}$ \\ Fakultas Sains dan Teknologi, Universitas Labuhanbatu \\ harismunandaaar@gmail.com ${ }^{1)}$, masrizal120405@gmail.com²)
}

\begin{abstract}
Abstrak
Kebutuhan arang batok kelapa di dunia industri mengalami peningkatan setiap bulannya, hal ini disebabkan oleh semakin sedikitnya jumlah energi yang dihasilkan bumi. Peningkatan jumlah permintaan arang tersebut juga harus diimbangi oleh hasil dari produsen arang, untuk meningkatkan efektivas perusahaan dalam perkembangan usaha maka harus dilakukan manajemen yang baik dalam menghitung jumlah penjualan arang yang dihasilkan. Penjualan arang batok kelapa pada tiap tahun bisa mengalami peningkatan dan penurunan, tingkat penjualan pada tahun yang akan datang bisa diprediksi tingkat penjualannya dengan menggunakan metode Monte Carlo. Metode Monte Carlo adalah algoritma komputasi untuk mensimulasikan berbagai perilaku sistem, seperti sistem penjualan pada perusahaan, metode ini nantinya akan melakukan perhitungan secara komputasi dengan menggunakan bilangan acak yang akan menghasilkan nilai untuk tahun yang akan datang.
\end{abstract}

\section{Kata Kunci: Penjualan, Metode Monte Carlo, Simulasi.}

\section{PENDAHULUAN}

Dewasa ini perkembangan teknologi informasi sangat pesat, semua masalah yang kompleks juga sudah bisa diselesaikan dengan mudah. Setiap permasalahan bisa dicontohkan dengan sebuah bentuk dan disimulasikan terlebih dahulu sebelum dikerjakan. Simulasi penjualan merupakan langkah- langkah yang efektif menggunakan metode ilmiah untuk melakukan pemasaran, agar tujuan dapat diperoleh dan mendapat manfaat dari padanya . Simulasi ini berdasarkan sebuah algoritma yang memperkirakan hasil

dari uji coba yang dilakukan demi mendapatkan ouput yang lebih baik untuk kedepannya. atau metode untuk menganalisa pergeseran ketidakpastian, di mana tujuannya adalah untuk menentukan bagaimana hasil perbedaan antara random dan error mempengaruhi sensitivitas, performa atau reliabilitas dari sistem yang ada sedang dimodelkan.

Penelitian ini menggunakan metode Monte Carlo, metode Monte Carlo adalah simulasi non-deterministik metode, kelas komputasi yang luas algoritma yang mengandalkan pengambilan sampel acak berulang .

Keuntungan utama metode Monte Carlo adalah intuitif dan mudah dipahami sebagai metode yang termasuk kategori uji statistik, kemudian mudah untuk menangani parameter karakteristik yang berubah-ubah secara acak dan mungkin menemukan beberapa faktor yang tidak dapat diprediksi dari perubahan proses, hasil analisa berupa prediksi tingkat penjualan pada masa yang 
akan datang. Menurut Sediva, dkk metode Monte Carlo mengatasi keterbatasan yang berlaku di kasus- kasus

tertentu dengan menggunakan perhitungan terkomputerisasi untuk melakukan propagasi distribusi probabilitas, distribusi probabitas

$$
\text { adalah suatu distribusi }
$$

yang mengambarkan peluang dari sekumpulan variat sebagai pengganti frekuensinya. Metode Monte Carlo, juga dikenal sebagai pengujian statistic metode, metode simulasi stokastik atau sampling acak metode, adalah perhitungan berdasarkan nomor acak . Itu Ide dasar dari metode Monte Carlo adalah variabelnya, yang mana mematuhi distribusi probabilitas, yang dirancang sesuai untuk informasi historis atau saran ahli, disimulasikan berulang-ulang dan beberapa

$$
\text { kesimpulan dilakukan }
$$

melalui penambahan dan menganalisis hasil simulasi.

Pengolahan arang batok kelapa saat ini mengalami perkembangan, sampai dengan tahun 2017 jumlah penjualan cukup bervariasi

selama 1 tahun terakhir, hampir semua kualitas mengalami kenaikan dan penurunan. Oleh sebab itu, dibutuhkan sebuah simulasi yang bisa memprediksi tingkat penjualan yang akan datang, simulasi dapat dihitung menggunakan persamaan-persamaan matematik . Namun karena begitu banyaknya data yang ingin dihitung maka mengharuskan penggunaan suatu perangkat yang disebut komputer agar model yang disimulasikan memiliki kemiripan sesuai dengan aslinya [11]. Berdasarkan analisis sebelumnya, maka penelitian ini bertujuan untuk mensimulasikan penjualan secara analisis dan terkomputerasi, agar menjadi gambaran untuk penjualan pada tahun yang akan datang.

\section{Metode Penlitian}

Pada bagian ini menjelaskan mengenai tahapan-tahapan yang dilakukan oleh penulis dalam melakukan simulasi monte carlo dalam memprediksi penjualan arang batok pada tahun yang akan datang, tahapan tersebut dapat dilihat pada gambar 1 berikut ini.

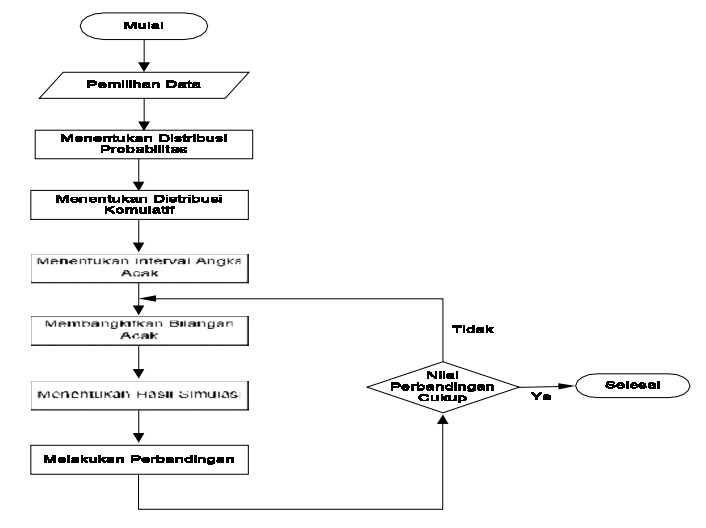

Gambar 1. Bentuk State of Process

Berdasarkan tahapan penelitian yang terdapat pada Gambar 1, dapat dilihat bahwa untuk melakukan simulasi monte carlo terdiri dari 7 tahapan, setiap tahapan memiliki aturanaturan dalam menentukan nilainya seperti tahapan menentukan distribusi probabilitas, menentukan distribusi komulatif, menentukan interval angka acak, menentukan bilangan acak, menentukan hasil simulasi dan menentukan perbandingan. Pada awalnya sebelum melakukan perhitungan simulasi terlebih dahulu menyiapkan data penjualan real yang sudah ada.

\section{Data}

Data yang akan dijadikan bahan simulasi merupakan data historical atau data terdahulu. Data yang diambil adalah data penjualan 1 tahun terakhir yaitu tahun 2017 . Data dibuat dengan menggunakan atribut Bulan, Penjualan, seperti, bulan, biaya bahan baku, 
jumlah penjualan, dan gaji karyawan. Data yang akan dijadikan simulasi adalah data penjualan selama 12 bulan. Jumlah keseluruhan penjualan berdasarkan penjumlahan dari bulan januari sampai dengan desember adalah sebesar Rp.1.422.500.000. Biaya Bahan Baku. Data yang direkap adalah data dari Tahun 2017.

Tabel 1. Rekap Data Penjualan 2017

\begin{tabular}{|c|c|c|c|}
\hline Bulan & $\begin{array}{c}\text { Biaya Bahan } \\
\text { Baku }\end{array}$ & Penjualan & $\begin{array}{c}\text { Gaji } \\
\text { Karyawan }\end{array}$ \\
\hline Januari & Rp60.000.000 & Rp93.750.000 & Rp3.000.000 \\
\hline Februari & Rp62.000.000 & Rp96.875.000 & Rp3.000.000 \\
\hline Maret & Rp62.800.000 & Rp98.125.000 & Rp3.000.000 \\
\hline April & Rp68.000.000 & Rp106.250.000 & Rp3.000.000 \\
\hline Mei & Rp80.000.000 & Rp125.000.000 & Rp3.000.000 \\
\hline Juni & Rp75.600.000 & Rp118.125.000 & Rp3.000.000 \\
\hline Juli & Rp76.000.000 & Rp118.750.000 & Rp3.000.000 \\
\hline Agustus & Rp78.000.000 & Rp121.875.000 & Rp3.000.000 \\
\hline September & Rp84.000.000 & Rp131.250.000 & Rp3.000.000 \\
\hline Oktober & Rp88.000.000 & Rp137.500.000 & Rp3.000.000 \\
\hline Nopember & Rp86.000.000 & Rp134.375.000 & Rp3.000.000 \\
\hline Desember & Rp90.000.000 & Rp140.625.000 & Rp3.000.000 \\
\hline Total & Rp910.400.000 & Rp1.422.500.000 & Rp36.000.000 \\
\hline
\end{tabular}

Berdasarkan Tabel 1. data yang sudah diuraikan didalam tabel dibagi beberapa bagian menghitung distribusi probabilitas

Tabel 2. Distribusi Probabiltas

\begin{tabular}{|c|c|c|}
\hline Bulan & Frekuensi Penjualan & $\begin{array}{c}\text { Distribusi } \\
\text { Probabilitas }\end{array}$ \\
\hline 1 & $\mathrm{Rp} 156.250 .000$ & 0,08 \\
\hline 2 & $\mathrm{Rp} 159.375 .000$ & 0,08 \\
\hline 3 & $\mathrm{Rp} 162.500 .000$ & 0,08 \\
\hline 4 & $\mathrm{Rp} 161.250 .000$ & 0,08 \\
\hline 5 & $\mathrm{Rp} 168.750 .000$ & 0,08 \\
\hline 6 & $\mathrm{Rp} 171.875 .000$ & 0,08 \\
\hline 7 & $\mathrm{Rp} 172.500 .000$ & 0,08 \\
\hline 8 & $\mathrm{Rp} 175.000 .000$ & 0,09 \\
\hline 9 & $\mathrm{Rp} 176.250 .000$ & 0,09 \\
\hline 10 & $\mathrm{Rp} 165.625 .000$ & 0,08 \\
\hline 11 & $\mathrm{Rp} 168.750 .000$ & 0,08 \\
\hline 12 & $\mathrm{Rp} 175.000 .000$ & 0,09 \\
\hline Jumlah & $\mathrm{Rp} 2.163 .125 .000$ & $\mathbf{1}$ \\
\hline
\end{tabular}

Untuk menghitung distribusi kumulatif pada setiap nilai keuntungan dari bulan Januari sampai Desember yaitu dengan menjumlahkan distribusi probabilitas yang telah dihitung dengan nilai probabilitas kumulatif di bulan sebelumnya.

\section{Hasil Dan Pembahasan \\ Menentukan Distribusi Probabilitas}

Pada tahap ini, penentuan distribusi probabilitas merupakan langkah awal dalam melakukan simulasi. Penetapan distribusi probabilitas untuk variabel-variabel penting yakni dengan cara membagi nilai tiap transaksi dengan jumlah variabel dari keseluruhan transaksi. Jumlah nilai keseluruhan transaksi dihasilkan dari penjumlahan keseluruhan transaksi dari bulan ke-1 sampai dengan bulan ke-12.

$$
\text { Distribusi Probabilitas } \mathrm{ke}-\mathrm{i}=\begin{gathered}
\mathrm{junSa} h \text { frekuenci ke- } \mathrm{i} \\
\text { total frekuensi (n) }
\end{gathered}
$$

nilai distribusi kumulatif sebelumnya dengan nilai distribusi probabilitas variabel tersebut.

Tabel 2. Distribusi Probabiltas

\begin{tabular}{|c|c|c|}
\hline Bulan & Frekuensi Penjualan & $\begin{array}{c}\text { Distribusi } \\
\text { Probabilitas }\end{array}$ \\
\hline 1 & Rp156.250.000 & 0,08 \\
\hline 2 & Rp159.375.000 & 0,08 \\
\hline 3 & Rp162.500.000 & 0,08 \\
\hline 4 & Rp161.250.000 & 0,08 \\
\hline 5 & Rp168.750.000 & 0,08 \\
\hline 6 & Rp171.875.000 & 0,08 \\
\hline 7 & Rp172.500.000 & 0,08 \\
\hline 8 & Rp175.000.000 & 0,09 \\
\hline 9 & Rp176.250.000 & 0,09 \\
\hline 10 & Rp165.625.000 & 0,08 \\
\hline 11 & Rp168.750.000 & 0,08 \\
\hline 12 & Rp175.000.000 & 0,09 \\
\hline Jumlah & Rp2.163.125.000 & $\mathbf{1}$ \\
\hline
\end{tabular}


Untuk menghitung distribusi probabilitas yaitu dengan mentotalkan seluruh jumlah frekuensi penjualan, kemudian jumlah frekuensi tiap bulannya dibagi dengan frekuensi total.

Sebagai contoh pada bulan ke-1 sebagai berikut:

Distribusi Probabilitas bulan ke- $1=156.250 .000=0,08$

\section{Menentukan Distribusi Kumulatif}

Untuk mendapatkan distribusi kumulatif pada setiap variabel dilakukan penjumlahan. Untuk menghitung distribusi kumulatif pada setiap nilai keuntungan dari bulan Januari sampai Desember yaitu dengan menjumlahkan distribusi probabilitas yang telah dihitung dengan nilai probabilitas kumulatif di bulan sebelumnya. Misalnya pada bulan ke-1 dan ke-2 seperti berikut ini

\footnotetext{
Distribusi kumulatif ke- $1=0,06+0 \quad=0,06$

Distribusi kumulatif ke-2 $=0,06+0,07=0,13$
}

Untuk menghitung distribusi kumulatif pada setiap nilai keuntungan dari bulan Januari sampai Desember yaitu dengan menjumlahkan distribusi probabilitas yang telah dihitung dengan nilai probabilitas kumulatif di bulan sebelumnya. Misalnya pada bulan ke-1 dan ke2 seperti berikut ini :

\section{Membangkitkan Bilangan Acak}

Pada tahapan ini membangkitkan bilangan acak dilakukan dengan memilih angka acak kemudian menentukan nilai mod yang akan digunakan. Bilangan acak (generating random number) menggunakan nilai input yang dipilih adalah $\mathrm{a}=13, \mathrm{Zi}=19$, $\mathrm{C}=29, \bmod =99$.

Sedangkan pembangkitan angka acak dengan menggunakan persamaan sebagai berikut:

$$
\begin{aligned}
& \mathrm{a} \cdot \mathrm{Zi}+\mathrm{C} \\
& \mathrm{Zi}+1=(\mathrm{a} \cdot \mathrm{Zi}+\mathrm{C}) \bmod \mathrm{M}
\end{aligned}
$$

\section{Tabel 3. Bentuk Bilangan Acak untuk 12} Bulan

\begin{tabular}{|r|c|c|c|}
\hline $\mathbf{1}$ & $\mathbf{Z i}$ & (a.zi+c) & zi+1=(a.zi+c) $\mathbf{m o d} \mathbf{~ m}$ \\
\hline 0 & 19 & 276 & 78 \\
\hline 1 & 78 & 1043 & 53 \\
\hline 2 & 53 & 718 & 25 \\
\hline 3 & 25 & 354 & 57 \\
\hline 4 & 57 & 770 & 77 \\
\hline 5 & 77 & 1030 & 40 \\
\hline 6 & 40 & 549 & 54 \\
\hline 7 & 54 & 731 & 38 \\
\hline 8 & 38 & 523 & 28 \\
\hline 9 & 28 & 393 & 96 \\
\hline 10 & 96 & 1277 & 89 \\
\hline 11 & 89 & 1186 & 97 \\
\hline
\end{tabular}

Pada Tabel 4. dapat dilihat bilangan acak selama 12 bulan, bilangan-bilangan tersebut didapat berdasarkan perhitungan persamaan angka acak. Nilai angka acak akan menjadi kriteria dalam penentuan hasil simulasi yang akan didapat. Nilai angka acak ini tidak selalu mempunyai angka yang sama setiap tahunnya. simulasi dari setiap transaksi dan ditentukan 
berdasarkan nilai distribusi kumulatif. Nilai interval angka acak dapat dilihat pada tabel berikut:

Tabel 4. Bentuk Bilangan Acak untuk 12 Bulan

\begin{tabular}{|c|c|c|c|c|}
\hline Bulan & $\begin{array}{c}\text { Freqwensi } \\
\text { Penjualan }\end{array}$ & $\begin{array}{c}\text { Distribusi } \\
\text { Probabilit } \\
\text { as }\end{array}$ & $\begin{array}{c}\text { Distribusi } \\
\text { Kumulatif }\end{array}$ & $\begin{array}{c}\text { Interval } \\
\text { Angka } \\
\text { Acak }\end{array}$ \\
\hline 1 & Rp156.250.000 & 0,08 & 0,08 & $00-08$ \\
\hline 2 & Rp159.375.000 & 0,08 & 0,16 & $09-15$ \\
\hline 3 & Rp162.500.000 & 0,08 & 0,24 & $16-23$ \\
\hline 4 & Rp161.250.000 & 0,08 & 0,32 & $24-31$ \\
\hline 5 & Rp168.750.000 & 0,08 & 0,40 & $32-39$ \\
\hline 6 & Rp171.875.000 & 0,08 & 0,49 & $40-48$ \\
\hline 7 & Rp172.500.000 & 0,08 & 0,57 & $49-56$ \\
\hline 8 & Rp175.000.000 & 0,09 & 0,66 & $57-65$ \\
\hline 9 & Rp176.250.000 & 0,09 & 0,75 & $66-74$ \\
\hline 10 & Rp165.625.000 & 0,08 & 0,83 & $75-82$ \\
\hline 11 & Rp168.750.000 & 0,08 & 0,91 & $83-90$ \\
\hline 12 & Rp175.000.000 & 0,09 & 1,00 & $91-99$ \\
\hline Jumlah & Rp2.163.125.000 & $\mathbf{1}$ & $\mathbf{6 , 4 0}$ & \\
\hline
\end{tabular}

Tabel 5, menjelaskan interval angka acak penjualan yang dimulai dengan interval 00 sampai 07 (termasuk 00 dan 07), berarti jumlah penjualannya adalah Rp. 156.250.000. Jika bilangan acak berada di interval 09 sampai 16Menetapkan Interval Angka Acak

Penetapan interval angka acak dilakukan untuk setiap variabel. Pada penelitian ini angka acak yang digunakan bernilai 00-99, sehingga nilai distribusi kumulatif dikonversikan ke nilai angka acak untuk setiap variabelnya. Penggunaan angka acak berfungsi untuk menetapkan interval nilai dari setiap variabel. Tahapan ini juga memberikan acuan hasil berarti jumlah penjualannya adalah Rp. 159.375.000, begitu seterusnya hingga interval 99 .

\section{Hasil Simulasi}

Hasil simulasi dapat ditentukan dengan cara menggunakan nilai angka acak dengan nilai yang dihasilkan dari penetapan interval angka acak, maka akan terlihat jumlah keuntung untuk durasi 12 bulan kedepan. Hasil simulasi dapat dilihat pada tabel berikut :

\section{Tabel 5. Hasil Simulasi Penjualan}

\begin{tabular}{|c|c|c|}
\hline $\begin{array}{c}\text { Bulan } \\
\text { Ke }\end{array}$ & Angka Acak & Simulasi \\
\hline 1 & 78 & $\mathrm{Rp} 137.500 .000$ \\
\hline 2 & 53 & $\mathrm{Rp} 121.875 .000$ \\
\hline 3 & 25 & $\mathrm{Rp} 106.250 .000$ \\
\hline 4 & 57 & $\mathrm{Rp} 121.875 .000$ \\
\hline 5 & 77 & $\mathrm{Rp} 137.500 .000$ \\
\hline 6 & 40 & $\mathrm{Rp} 118.125 .000$ \\
\hline 7 & 54 & $\mathrm{Rp} 121.875 .000$ \\
\hline 8 & 38 & $\mathrm{Rp} 118.125 .000$ \\
\hline 9 & 28 & $\mathrm{Rp} 125.000 .000$ \\
\hline 10 & 96 & $\mathrm{Rp} 140.625 .000$ \\
\hline 11 & 89 & $\mathrm{Rp} 134.375 .000$ \\
\hline 12 & 97 & $\mathrm{Rp} 140.625 .000$ \\
\hline & Total & $\mathrm{Rp} 1.524 .375 .000$ \\
\hline
\end{tabular}

\section{Kesimpulan}

Berdasarkan hasil penelitian yang sudah dilakukan, bahwa hasil simulasi untuk tahun 2017 bisa dijadikan gambaran untuk setiap bulannya pada tahun 2018, kemudian setelah nanti didapat angka penjualan pada tahun 2018 bisa dilakukan 
perbandingan tingkat penjualan pada tahun sebelumnya.

\section{Daftar Pustaka}

C. Republic, "Application of the Monte Carlo Method to Estimate the Uncertainty of Air Flow Measurement," pp. 465-469, 2015.

H. Huang, F. Li, and Y. Mishra, "Ref3_Modeling Dynamic Demand Response Using Monte Carlo Simulation and Interval Mathematics for Boundary Estimation," Smart Grid IEEE, pp. $1-10,2015$.

B. Yu, Y. Li, Y. J. Xiao, X. L. Luo, and Z. M. Ou, "Simulation modeling for weakening bullwhip effect in autosales," 2011 IEEE 18th Int. Conf. Ind. Eng. Eng. Manag. IE EM 2011, no. PART 3, pp. 1518-1522, 2011.

L. Haoyu, J. A. Russer, C. Wenquan, and P. Russer, "A Monte Carlo method approach for the solution of the Helmholtz equation," 2015 AsiaPacific Microw. Conf., no. 4, pp. $1-3,2015$.

P. Dengan, M. Simulasi, M. Carlo, S. Kasus, and D.

I. Pt, "Optimasi persediaan," vol. 4, no. 3, pp. 166-174, 2016.

S. E. K. Osman, R. Mahmoud, S. F. Babiker, and $\mathrm{S}$.

M. Ieee, "Aggregate Path MonteCarlo Method for Single Electron Circuit Simulations," pp. $8-11$, 2015.

W. Chun, L. Kexin, H. Mingliang, and D. Jing, "On the radar detection analysis under the interference environment based on the Monte Carlo method," ISAPE 2016 - Proc. 11th Int. Symp. Antennas, Propag. EM Theory, 2017.

S. Array, M. Signal, and P. Workshop, "SAMPLING SIZE IN MONTE CARLO BAYESIAN

COMPRESSIVE SENSING Ioannis Kyriakides Department of Electrical Engineering University of Nicosia , Cyprus Radmila Pribi ' c Sensors Advanced Developments Thales Nederland Delft, The Netherlands," pp. 397-400, 2014.

S. Daoyuan, "The Application of Monte Carlo Computer Simulation in Economic Decision- making," no. Iccasm, pp. 592-595, 2010.

L. Bertot, S. Genaud, and J. Gossa, "An overview of cloud simulation enhancement using the monte-carlo method," Proc. - 18th IEEE/ACM Int. Symp. Clust. Cloud Grid Comput. CCGRID 2018, pp. 386-387, 2018.

S. Sheng, D. Xianzhong, and W. L. Chan, "Probability distribution of fault in distribution system," IEEE Trans. Power Syst., vol. 23, no. 3, pp. 1521-1522, 2008. 